Проскурнина Н.Н. Ласковый А.А. Швыдченко Н.В.

Управление экономической активностью молодежи

Проскурнина Н.Н., кандидат социологических наук, доцент, доцент кафедры «Экономика и управление на предприятии», Институт сервиса, туризма и дизайна (филиал) СКФУ в г. Пятигорске;

Ласковъй А.А., кандидат экономических наук, доцент, доцент кафедры «Экономика и управление на предприятии», Институт сервиса, туризма и дизайна (филиал) СКФУ в г. Пятигорске;

Швъдченко Н.В., старший преподаватель кафедры «Экономика и управление на предприятии», Институт сервиса, туризма и дизайна (филиал) СКФУ в г. Пятигорске

\section{УПРАВЛЕНИЕ ЭКОНОМИЧЕСКОЙ АКТИВНОСТЬЮ МОЛОДЕЖИ}

Социально-экономический потенциал любой страны в настоящее время и в будущем напрямую зависят от экономической активности молодежи, для которой участие в экономической деятельности является, в свою очередь, значимым фактором социокультурного и профессионального становления [1]. Рыночная экономика, с одной стороны, значительно расширила пределы приложения сил и способностей молодежи, с другой - обусловила ослабление еe государственной поддержки в социально-экономической сфрере, пошатнула старые институциональные основы социализации молодежи в условиях несформированности новых.

В данном контексте стратегическое и оперативное управление экономической активностью молодежи становится одной из главных задач государственных органов и учреждений.

Очевидно, что проблематика управления экономической активностью молодежи не нова, но глобальный экономический кризис наглядно продемонстрировал и углубил существующие в молодежном сегменте проблемы, связанные с недостатками функционирования рынков труда, несоответствием потребностей работодателей и системы образования, недостаточностью усилий государства в борьбе с молодежной безработицей.

Практическая значимость вопросов управления экономической активностью молодежи усиливается значимостью научной, которая бази-

Серия 2. Гуманитарные науки, 2015, № 2 
руется на необходимости углубления исследований в сфере государственного управления социальным становлением и развитием молодых граждан.

Все это подтверждает актуальность темы исследования и обусловливает его цель.

Изучению различных аспектов управления экономической активностью молодежи, особенностей обеспечения занятости ее отдельных категорий посвящены научные труды: Кочиной Е.А., Шишкиной А.Ю., Корниенко Т.А., Косенко С.Г., Бендриковой А.Ю., Бухнера Н.Ю. и др. Однако существенные трансформационные сдвиги, происходящие в настоящее время, вызывают необходимость активизации исследований в направлении поиска новой парадигмы управления экономической активностью молодежи.

Таким образом, с учетом вышеизложенного, цель статьи заключается в проведении анализа мирового опыта управления экономической активностью молодежи, выявлении наиболее успешных и эффрективных практик, а также проблем сопровождающих данных процесс.

Не подвергается сомнению тот факт, что управление экономической активностью молодежи нельзя рассматривать отдельно от конкретноисторических обстоятельств, общих социально-экономических тенденций, а также ближайших или более отдаленных перспектив. В мировом масштабе доминирующими становятся новые подходы к работе с молодежью, которые предусматривают ее соответствие фракторам человеческого развития, поддерживаются адекватностью форм и методов институционального характера, работают на опережение.

Определяющим для молодежи является ее успешное вхождение в производственно-трудовую деятельность. Именно на этом этапе своей жизни молодые люди сталкиваются с трудностями и нуждаются в понимании и помощи как со стороны старшего поколения, так и со стороны государства [2]. Итак, вызовом для общества на глобальном уровне в сфере управления экономической активностью молодежи является предоставление ей возможностей получить продуктивную занятость и достойный труд. При этом фундаментальное значение для расширения возможностей молодежи и самореализации личности имеет образование, направленное на трудоустройство и воспитание способности участвовать в устойчивом развитии общества.

Исследование этих процессов в развитых странах мира позволило установить следующее.

В Европейском Союзе молодежь рассматривается не как проблема, a, прежде всего, как человеческий капитал, который накапливается по четко обозначенным фазам жизненного цикла и требует инвестирования с помощью различных институтов и проектов общества [3].

Учитывая этот тезис, государственная политика по управлению экономической активностью молодежи в Европе начала ориентиро-

\section{НАУЧНОЕ ОБОЗРЕНИЕ}


ваться на индивидуальные стремления и приоритеты самого человека, что отразилось на тенденциях работы с молодежью. Акцент на значимость молодежных объединений и организаций потерял свою актуальность. Вместо этого развитие получили программы и проекты, которые направлены на работу не с группами, а с конкретными молодыми людьми. Прежде всего, это реализовалось в создании благоприятных условий для развития желания молодого человека работать и активно участвовать в жизни общества [4].

EC разработал широкий набор целевых программ, направленных на преодоление социального отторжения и социальное вовлечение. Вместе с тем происходит поощрение молодежного творчества, инициативы и достижений комплексом государственных премий и льгот, грантовых программ, формирование образа активной молодежи, преуспевающей в рамках закона и норм общественной морали.

Как следствие, учитывая, что доля молодежи в составе населения европейских стран, начиная с 1990-х гг., последовательно снижается, показатели экономической активности молодежи постепенно растут [5].

Несомненно, внимание управлению экономической активности молодежи уделяется и в развивающихся государствах. При этом надо отметить, что реализация государственной молодежной политики, например, в странах СНГ осуществляется на достаточно низком уровне. Это обусловлено проявле- нием острого кризиса традиционных институтов социализации молодого поколения, технологической и структурной перестройкой в обществе, слабым развитием экономики, сегментацией рынка труда, несоответствием между образованием и профессиональным обучением и др. Как следствие, по итогам 2013 года в Казахстане уровень молодежной безработицы составил 3,9\%, в Армении - почти 39\%, превысив в 2,2 раза средний по региону показатель. Удельный вес молодежи в общей численности официально зарегистрированных безработных, например, в Молдове в 2013 г. составил $35 \%$, Беларуси - 42\%, России - 43\%, Казахстане и Азербайджане - почти 60\% [6].

Принимая во внимание вышеизложенное, представляется, что с целью усовершенствования системы управления экономической активностью молодежи в постсоветских странах необходимо:

- разработать и принять действенную законодательную и нормативную базу по осуществлению государственной молодежной политики;

- создать структуры, отвечающие за координацию действий в сфере государственной молодежной политики;

- активно привлекать молодежь, ее общественные организации к осуществлению государственной молодежной политики.

Кроме того, постсоветским странам следует придерживаться ключевых принципов управления экономи- 
ческой активностью молодежи:

1) принцип участия. Он означает, что субъектом разработки и реализации управления экономической активностью молодежи является, прежде всего, сама молодежь, ее объединения и организации. Особое место в этом принципе отводится организованным структурам молодежного движения. Согласно мировой практике, государство в сотрудничестве с ними реализует так называемый принцип субсидиарности, то есть предоставляет средства не в порядке государственного меценатства, а как участникам государственно значимой деятельности по развитию потенциала молодого поколения;

2) принцип равенства и доступноcmu. Этот принцип признает права и обязанности всех молодых людей относительно равных возможностей и равного распределения услуг и ресурсов. Молодежь имеет право на равный доступ к программам и услугам независимо от пола, места жительства, социального, культурного, экономического факторов;

3) принцип гарантий. Согласно ему, государство предоставляет всем молодым гражданам минимум государственных социальных услуг, касающихся образования, воспитания, духовного и физического развития, профессиональной подготовки и трудоустройства. Дальнейшее развитие личности, ее самореализа- ция - это, прежде всего, результат усилий самого человека, его самосовершенствования. $\mathrm{OH}$ стимулируется различными способами, в том числе кредитованием, системой рациональных льгот, определением и поощрением лучших и лучшей деятельности;

4) принцип социальной компенсации. В этом случае речь идет о правовой и социальной защите именно тех молодых людей, которые по собственному социальному статусу и состоянию здоровья сами не способны о себе позаботиться (дети из неполных или многодетных семей, сироты, молодые инвалиды и т.д.).

Таким образом, подводя итоги проведенному исследованию можно сделать следующие выводы. В контексте преодоления просткризисного спада вопросы эффективного управления экономической активностью молодежи приобретают особую актуальность. Критическое значение обозначенная проблематика имеет для стран с догматическим и зарегулированным рынком труда, к их числу, например, относятся бывшие республики Советского Союза. Проанализированный опыт развитых государств, свидетельствует о том, что они используют новую парадигму в управлении экономической активностью молодежи, которая предусматривает переориентацию на индивидуальные предпочтения и приоритеты самого человека.

\section{НАУЧНОЕ ОБОЗРЕНИЕ}


В процессе исследования сформулированы рекомендации, касающиеся оптимизации и повышения результативности процесса управ- ления экономической активностью молодежи, выделены ключевые принципы, которые должны составлять основу данного процесса.

\section{Список литературь}

1. Нигматуллина Т.А. Формирование потенциала молодежи в новой системе социокультурных координат // Вопросы национальных и федеративных отношений. 2013. - № 2(21). - С. 72-78.

2. Зернов Д.В., Иудин А.А., Овсянников А.А. Социальное самочувствие советского и постсоветского студенчества // Народонаселение. - 2015. - № 1(67). - С. 50-68.

3. Working with young people the value of youth work in the European Union. - Luxembourg: Publications Office of the European Union, 2014. P. 186-190.

4. Gema M. García Albacete Young people's political participation in Western Europe: continuity or generational change? - Basingstoke: Palgrave Macmillan, 2014. 335 p.

5. EU: helping young people into employment. Equal opportunities review. ISSU 217; 2011, P. 16-17.

6. Калинюк Ю.В., Лаптева И.Д., Лощилова М.А., Морозова М.В., Павлючков Г.А., Демченко А.Р., Холина Л.А., Чичерина Н.В. Профессиональное самоопределение молодежи на региональном рынке труда как фактор устойчивой занятости // Сибирский педагогический журнал. - 2014. - № 6. - С. 85-92.

\section{Bibliography}

1. Nigmatullina T.A. Capacity building of young people in the new system of socio-cultural coordinates. Questions of national and federal relations. 2013. No 2(21). P. 72-78.

2. Zernov D.V., Iudin A.A., Ovsyannikov A.A. Social well-being of the Soviet and PostSoviet students. Population. 2015. № 1(67). P. 50-68.

3. Working with young people the value of youth work in the European Union. Luxembourg: Publications Office of the European Union. 2014. P. 186-190.

4. Gema M. García Albacete Young people's political participation in Western Europe: continuity or generational change? Basingstoke: Palgrave Macmillan, 2014. 335 p.

5. EU: helping young people into employment. Equal opportunities review. ISSU 217; 2011. P. 16-17.

6. Kalinyuk Yu.V., Lapteva I.D., Loschilova M.A., Morozova M.V., Pavlyuchkov G.A., Demchenko A.R., Holina L.A., Chicherina N.V. Professional self-determination of young people on the labor market as a factor of sustainable employment. Siberian Education Journal. 2014. No 6. P. 85-92. 